\title{
Human Myeloid Plasma Membrane Glycoprotein CD13 (gp150) Is Identical to Aminopeptidase $\mathbf{N}$
}

\author{
A. Thomas Look, Richard A. Ashmun, Linda H. Shapiro, and Stephen C. Peiper \\ Departments of Hematology-Oncology, Tumor Cell Biology, and Pathology and Laboratory Medicine, St. Jude Children's Research \\ Hospital, and the Division of Hematology and Oncology, Department of Pediatrics, the University of Tennessee, Memphis, \\ College of Medicine, Memphis, Tennessee 38101
}

\begin{abstract}
To determine the primary structure of $\mathrm{CD13}$, a $150-\mathrm{kD}$ cell surface glycoprotein originally identified on subsets of normal and malignant human myeloid cells, we isolated the complete sequences encoding the polypeptide in overlapping complementary DNA (cDNA) clones. The authenticity of our cDNA clones was demonstrated by the ability of the coding sequences, subcloned in a retroviral expression vector, to mediate expression of bona fide CD13 molecules at the surface of transfected mouse fibroblasts. The nucleotide sequence predicts a 967 amino acid integral membrane protein with a single, 24 amino acid hydrophobic segment near the amino terminus. Amino-terminal protein sequence analysis of CD13 molecules indicated that the hydrophobic segment is not cleaved, but rather serves as both a signal for membrane insertion and as a stable membrane-spanning segment. The remainder of the molecule consists of a large extracellular carboxyterminal domain, which contains a pentapeptide consensus sequence characteristic of members of the zinc-binding metalloprotease superfamily. Sequence comparisons with known enzymes of this class revealed that $\mathrm{CD13}$ is identical to aminopeptidase $\mathrm{N}$, a membrane-bound glycoprotein thought to be involved in the metabolism of regulatory peptides by diverse cell types, including small intestinal and renal tubular epithelial cells, macrophages, granulocytes, and synaptic membranes prepared from cells of the central nervous system.
\end{abstract}

\section{Introduction}

Normal human myeloid cells and their leukemic counterparts bear unique cell surface differentiation antigens which, by convention, are assigned to cluster differentiation $(C D)^{1}$ groups based on their specific reactivity with defined monoclonal an-

Address reprint requests to Dr. Look, Department of Hematology/Oncology, St. Jude Children's Research Hospital, P.O. Box 318, Memphis, TN 38101. Dr. Peiper's present address is the Department of Pathology, University of Alabama at Birmingham, Birmingham, AL 35294.

Received for publication 10 August 1988 and in revised form 10 November 1988.

1. Abbreviations used in this paper: CALLA, common acute lymphoblastic leukemia antigen; CD, cluster of differentiation; gp150, 150-kD cell surface glycoprotein (CD13); gp130, the 130-kD precursor of gp150.

J. Clin. Invest.

(c) The American Society for Clinical Investigation, Inc.

0021-9738/89/04/1299/09 \$2.00

Volume 83, April 1989, 1299-1307 tibodies (1). Antibodies used to identify the CD13 cluster group bind a $150-\mathrm{kD}$ cell surface glycoprotein (gp150) that is expressed by committed granulocyte-monocyte progenitors (CFU-GM) and by cells of the granulocytic and monocytic lineages at all morphologically distinct stages of differentiation (2-5). CD13 is also expressed by leukemic blasts from a high percentage of patients with acute myeloid leukemia $(2,6-10)$ and from a smaller group of patients with acute lymphoid leukemia (10-12) who have an increased risk of treatment failure, especially when the lymphoblasts coexpress CD13 epitopes and B-lineage markers (11). This molecule appears to be highly immunogenic: 11 monoclonal antibodies independently derived from mice immunized with human myeloid cells bound CD13 epitopes in studies reported at a recent international workshop $(1,13)$. These antibodies are termed MY7, MCS-2, SJ-1D1, WM-15, CLB-mon-gran/2, MoU28, MoU48, DU-HL60-4, 22A5, 72a, and 124a4. CD13-specific antibodies do not bind to normal B or $\mathrm{T}$ lymphocytes but do react with nonhematopoietic cells, including fibroblasts, osteoclasts, and cells that line renal proximal tubules and bile duct canaliculi (1).

Biochemical studies have demonstrated that CD13-specific antibodies immunoprecipitate a 130-kD glycoprotein (gp130), as well as gp150, from human myeloid leukemic cell lines (14, 15). Metabolic labeling studies established that gp130 is an intracellular precursor of gp150, differing from the larger cell surface form of the molecule in the composition of its carbohydrate chains. When cells were labeled in the presence of tunicamycin, an antibiotic that blocks the addition of asparagine-linked oligosaccharide chains, a single unglycosylated polypeptide of $110 \mathrm{kD}$ was immunoprecipitated $(14,15)$. A comparison of labeled tryptic cleavage products of gp130 and gp150 molecules confirmed that these glycoproteins have an identical primary structure and thus are posttranslationally modified products of a single gene (14).

Sequential rounds of DNA-mediated gene transfer and fluorescence-activated cell sorting were used to isolate the gene encoding CD13 in a mouse genetic background (14). Sequences from the CD13 locus that annealed to a human repeated sequence probe were cloned from a tertiary mouse cell transformant that had amplified the transfected human gene (16). Molecular subclones were then used to isolate the complete CD13 gene from a human placental genomic DNA library; the intact gene, assembled from three recombinant phages, encoded authentic gp150 glycoproteins when it was transfected into mouse fibroblasts. Probes prepared from subclones within the CD13 locus were used to identify a 4.0-kb RNA transcript expressed by human myeloid cells and to assign the CD13 gene to the distal long arm of chromosome 15.

We now report the isolation and characterization of overlapping cDNA clones which together contain all of the CD13 coding sequences. The deduced primary structure and $\mathrm{NH}_{2}-$ 
terminal amino acid sequence of gp 150 indicate that it is an integral membrane protein with a large extracellular carboxyterminal domain, a short intracellular amino-terminal segment, and a hydrophobic signal sequence that is retained and functions as the transmembrane domain. Moreover, the predicted amino acid sequence of CD13 is virtually identical to the recently determined sequence of aminopeptidase $\mathrm{N}$, a prominent intrinsic enzyme of the brush border membranes of the small intestine and renal proximal tubules.

\section{Methods}

cDNA cloning and DNA sequence analysis. We previously identified restriction fragments lacking human repetitive sequences that are included in the CD13 genomic locus and that anneal to a 4.0-kb RNA transcript expressed by the HL-60 and KG1 human myeloid leukemic cell lines (16). A mixture of these fragments was nick-translated and used as a probe to screen an oligo-dT primed lambda gt 11 cDNA library prepared with polyadenylated RNA from HL-60 cells (a gift of Dr. Michael Holers, Washington University, St. Louis, MO; 17). Additional clones were isolated from a cDNA library prepared in the lambda ZAP vector (Stratagene Corp., La Jolla, CA) with polyadenylated RNA from KG1 cells. First strand synthesis was initiated with random primers and with synthetic oligonucleotides inversely complementary to $5^{\prime}$ sequences of clones isolated from the oligo-dT primed library.

Eco RI inserts from the lambda gt 11 clones were subcloned into the pBluescript plasmid (Stratagene); lambda ZAP phages were rescued directly as recombinant pBluescript plasmids with procedures recommended by the manufacturer. Restriction endonuclease sites were mapped in the subcloned cDNA inserts, and restriction fragments were nick-translated and used as probes on Southern blots of digested DNA from both cDNA and genomic phage clones (16). In this way, the cDNA clones were oriented relative to each other and to the CD13 genomic locus. To determine the $5^{\prime}$ to $3^{\prime}$ orientation of the cDNA clones relative to messenger RNA, single-stranded RNA probes were prepared from selected cDNA inserts subcloned in pBluescript. Probes were transcribed from each strand of the cDNA insert with the T3- and T7-specific polymerases that bind specific promoter sequences flanking the cloning sites of this vector, using a kit supplied by Promega Biotec (Madison, WI). Each probe was hybridized to Northern blots, prepared as described previously (16), to determine which probe orientation was complementary to the 4.0-kb CD13 messenger RNA.

Based on an extensive map of restriction endonuclease sites within the inserts of the three longest cDNA clones $(\lambda 6, \lambda 29$ and $\lambda 71)$, a series of restriction fragments were subcloned into the $M 13 \mathrm{mp} 18$ and M13mp19 vectors for DNA sequence analysis by the Sanger dideoxy chain-termination method (18) using the Sequenase DNA sequencing kit (United States Biochemical Corp, Cleveland, $\mathrm{OH}$ ). The entire cDNA was sequenced on both strands and each cloning site was resequenced in overlapping subclones. The sequence was verified for each subclone by using fluorescent dye-labeled primers and the 370A automated DNA sequencer (Applied Biosystems). IntelliGenetics (Mountain View, CA) software was used for all sequence manipulation and analysis.

Expression of $c D N A$ sequences cloned in a retroviral vector. Full length CD13 cDNA was reconstructed by subcloning the $5^{\prime} 1.8 \mathrm{~kb}$ Eco RI insert of $\lambda 29$ (see Fig. 1) into a pBluescript plasmid containing the $3^{\prime}$ $1.6 \mathrm{~kb}$ Eco RI insert of $\lambda 6$, which had been linearized by partial digestion with Eco RI. The restriction sites in the resulting plasmids were mapped to identify a plasmid that contained both Eco RI cDNA restriction fragments ligated in the correct $5^{\prime}-3^{\prime}$ orientation. Sequencing analysis subsequently disclosed a 139-bp deletion in the insert of $\lambda 29$, by comparison with the corresponding sequence of $\lambda 71$ and other clones spanning this region. This deletion interrupted the CD13 open reading frame, and presumably represented a cloning artifact. There- fore, a 1.0-kb Nco I restriction fragment containing this region from $\lambda 71$ was substituted for the corresponding restriction fragment in the plasmid containing the reconstructed cDNA. The resulting pBluescript plasmid was digested with Sal I, which cut only in the cloning polylinker adjacent to the $5^{\prime}$ end of the CDNA and with Xba I, which cut once in the cDNA insert in the $3^{\prime}$ untranslated region upstream of the polyadenylation signal (see Fig. 2). The resulting 3.4-kb restriction fragment, which contained all of the predicted CD13 coding sequences, was inserted into the unique Bam HI site of the murine retroviral vector pZIPneoSV(X)-1 (19) provided by Dr. Richard C. Mulligan, Whitehead Institute, Boston, MA. Blunt end ligation was employed, after the recessed $3^{\prime}$ ends of both the insert and the vector had been filled in with the Klenow fragment of Escherichia coli polymerase I. Colonies containing recombinant plasmids were identified by hybridization, and a plasmid with the correct $5^{\prime}$ to $3^{\prime}$ orientation of the cDNA insert relative to the vector was selected on the basis of restriction endonuclease mapping.

This construction linked the CD13 gene to DNA sequences of the vector encoding neomycin resistance (neo); the gp 150 protein is translated from the unspliced retroviral RNA, whereas the neo product is synthesized from a spliced mRNA. The retroviral construct was transfected by the calcium phosphate method into NIH-3T3 cells (14). After transfection, the cells were cultured in medium containing $800 \mu \mathrm{g} / \mathrm{ml}$ of G418 (Geneticin; Gibco Laboratories, Grand Island, NY), to select for expression of the neo gene. G418-resistant cells were sorted by flow cytometry after they had been stained with the monoclonal antibody MY7 (Coulter Immunology, Hialeah, FL), which reacts with an epitope of gp150 $(2,14)$. Transfected cells isolated according to their reactivity with MY7 were tested by flow cytometry for binding of other monoclonal antibodies that react with epitopes of CD13: SJ-1D1 (20) from Dr. Joseph Mirro of St. Jude Children's Research Hospital, Memphis, TN; and MCS-2 (15) from Dr. Jun Minowada of Loyola University, Chicago, IL. Indirect immunofluorescence labeling, flow cytometric analysis, and cell sorting were performed as previously described (14).

Metabolic labeling and immunoprecipitation. Subconfluent cultures of cells were incubated at $37^{\circ} \mathrm{C}$ in $5 \mathrm{ml}$ methionine-free DMEM (Gibco Laboratories) containing 5\% dialyzed fetal calf serum for 30 min and then labeled for $60 \mathrm{~min}$ in $2 \mathrm{ml}$ of the same medium containing $0.25 \mathrm{mCi}$ of $\left[{ }^{35} \mathrm{~S}\right]$ methionine $(1,200 \mathrm{Ci} / \mathrm{mmol})$ per $\mathrm{ml}$. An equal volume of complete medium was added, and the incubation was continued for an additional $60 \mathrm{~min}$. The cells were rinsed in ice-cold PBS and lysed in RIPA buffer ( $50 \mathrm{mM}$ Tris hydrochloride [pH 7.4], 150 $\mathrm{mM} \mathrm{NaCl}, 20 \mathrm{mM}$ EDTA, $1 \%$ Triton $\mathrm{X}-100,1 \%$ sodium deoxycholate, $0.1 \%$ SDS) containing $2 \%$ aprotinin and $1 \%$ PMSF to inhibit proteases. The lysates were immunoprecipitated and separated by SDS-PAGE $(14,21)$; the mobilities of radiolabeled proteins were determined by autoradiography relative to known polypeptide standards.

Immunoprecipitation of glycoproteins for $\mathrm{NH}_{2}$-terminal protein sequence analysis. Exponentially growing HL-60 cells $\left(1 \times 10^{9}\right)$ were lysed in RIPA buffer and immunoprecipitated with antiserum specific for CD13 epitopes. For this immunoprecipitation, we used a CD13specific polyvalent antiserum produced by neonatal (8-d-old) NFS mice that are syngeneic with NIH-3T3 cells. Tumorigenic cells from the NIH-3T3 cell tertiary transformant SJ-150-B $(16,22)$, which coexpresses high levels of CD13 together with the transforming glycoprotein encoded by the v-fms oncogene, were injected subcutaneously into the mice. The animals with tumors were bled, and pooled sera were tested for their ability to react with CD13 in immunofluorescence and immunoprecipitation assays. As we had previously observed for similar antisera produced against epitopes of CD33 (23), pooled CD13-specific antiserum proved superior to monoclonal antibodies for precipitating large quantities of the gp130 and gp 150 glycoproteins, presumably because it recognizes multiple epitopes with high affinity. The immunoprecipitates were separated by SDS-PAGE, and gp 150 and its gp130 precursor were transferred to Immobilon membranes (Miles Laboratories, Elkhart, IN) following methods of Matsudaira (24), and visualized by Coomassie blue staining. The $\mathrm{NH}_{2}$-terminal amino acid 
sequences of both the gp130 and gp150 forms of the molecule were determined from two independent preparations according to established procedures $(24,25)$.

\section{Results}

Isolation of $C D 13$ cDNA clones. Unique sequence probes derived from the CD13 genomic locus were used to screen cDNA libraries that were prepared with polyadenylated RNA extracted from human myeloid cell lines that express CD13. 12 strongly hybridizing clones were isolated from a cDNA library primed with oligo-dT, and 10 additional clones were obtained from a library primed with a mixture of random primers and specific oligonucleotides representing sequences inversely complementary to 5' CD13 sequences. Restriction endonuclease cleavage sites were determined for the three clones with the largest inserts; defined restriction fragments were then used as probes in Southern blotting experiments to align the cDNA clones and to establish their orientation relative to previously isolated genomic clones (Fig. 1). Together, the overlapping cDNA clones spanned $3.5 \mathrm{~kb}$ of the CD13 messenger RNA, which was estimated to be $4.0 \mathrm{~kb}$ in length as judged from Northern blots hybridized with the same genomic probes that were used to isolate the cDNA clones (16).

When used as probes for Southern blots of restriction digests of previously isolated genomic clones, the cDNA restriction fragments hybridized to a region of $\sim 20 \mathrm{~kb}$ (Fig. 1). Genomic clones containing this region mediate expression of
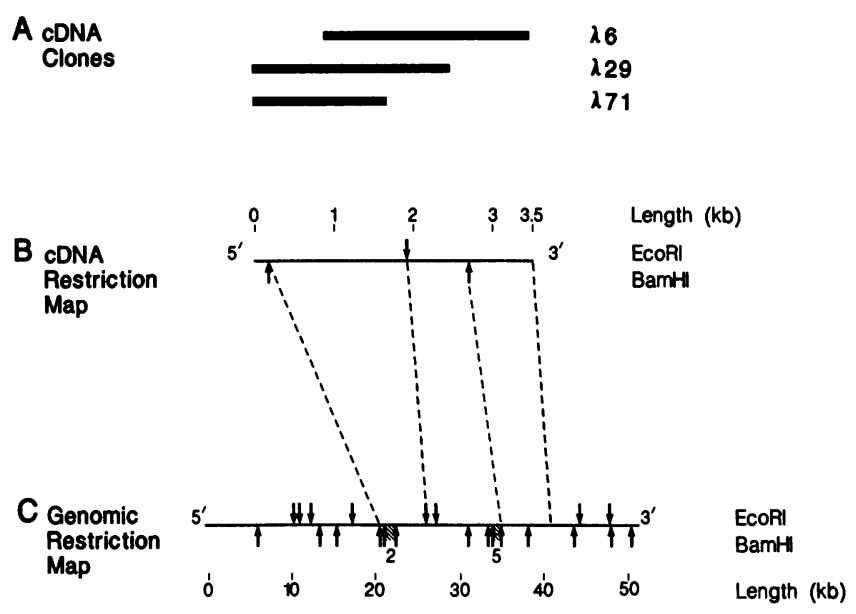

Figure 1. Restriction map of CD13 cDNA clones $(A$ and $B)$, in relation to the restriction map of the previously isolated genomic locus (C). Clones $\lambda 6$ and $\lambda 29$ were isolated from an oligo-dT primed cDNA library made from HL-60 cell mRNA, using a probe prepared from a mixture of two unique sequence genomic restriction fragments (labeled 2 and $5, C$ ) that had been previously shown to hybridize with the $4.0 \mathrm{~kb}$ CD13 mRNA. Clone $\lambda 71$ was isolated from a cDNA library prepared from KGl cell mRNA by using a mixture of random primers and oligonucleotides inversely complementary to $5^{\prime}$ sequences from $\lambda 29$. The inserts of these clones contained one internal Eco RI site and two Bam HI sites, with positions as shown in $B$. The corresponding restriction sites in the CD13 genomic map (dashed lines connecting $B$ with $C$ ) were identified with cDNA probes from Bam HI-Eco RI restriction fragments of the inserts of $\lambda 6$ and $\lambda 29$ to probe Southern blots of restriction digests of previously isolated phage clones that span the CD13 genomic locus (16). gp 150 when appropriately ligated together and transfected into mouse fibroblasts (16). The $5^{\prime}$ to $3^{\prime}$ orientation of the cDNA clones shown in Fig. 1 was determined by hybridizing strandspecific RNA probes prepared from cDNA restriction fragments subcloned in the pBluescript transcription vector to Northern blots of polyadenylated RNA from myeloid cell lines. RNA probes prepared from restriction fragments cloned in an antisense orientation hybridized to the $4.0 \mathrm{~kb} \mathrm{CD13}$ messenger RNA (data not shown).

CD13 cDNA sequence. The complete nucleotide sequence of overlapping CD13 cDNA inserts contained in the $\lambda 6, \lambda 29$, and $\lambda 71$ clones extends for 3,494 nucleotides and is flanked by a poly(A) sequence at its $3^{\prime}$ end (Fig. 2). The longest predicted open reading frame of 2901 residues (nucleotides 121-3021) is preceded by 120 nucleotides of $5^{\prime}$ untranslated sequence and terminates with 473 nucleotides of $3^{\prime}$ untranslated sequence. A polyadenylation signal (AATAAA) (26) is located 13 nucleotides upstream from the poly $(\mathrm{A})$ sequence at the $3^{\prime}$ end of the cDNA. The first ATG codon, at position 121, matches the consensus sequence for a translation initiation site (27). Seven residues separate the initiator methionine from a hydrophobic region of 24 amino acids, which is likely to represent a signal peptide sequence necessary for transport of the nascent polypeptide chains into the lumen of the endoplasmic reticulum. The deduced amino acid sequence of the CD13 polypeptide predicts a total of 967 amino acids with a molecular mass of $110 \mathrm{kD}$, in agreement with the apparent mass of the unglycosylated CD13 polypeptide synthesized by cells grown in the presence of tunicamycin $(14,15) .11$ canonical sites (Asn-X$\mathrm{Ser} / \mathrm{Thr}$ ) for the addition of asparagine-linked oligosaccharide chains are present $3^{\prime}$ to the putative membrane-spanning segment. Nearly all of these potential sites may be utilized, because each high-mannose chain has an estimated mass of 2.5 $\mathrm{kD}$, and immature gp130 precursor molecules differ by $\sim 20$ $\mathrm{kD}$ from the mass of the unglycosylated polypeptide. Five cysteine residues are distributed over the polypeptide sequence. Because the CD13 mRNA is estimated to be $4.0 \mathrm{~kb}$ by Northern blot analysis, and our cDNA clones span 3494 nucleotides, the native transcripts most likely contain additional untranslated nucleotides at their $5^{\prime}$ ends.

The entire CD13 cDNA and protein sequences were used to search for similarity with other sequences available from the NIH DNA sequence library (GenBank; Release 56), the European Molecular Biology Laboratory DNA sequence library (EMBL; Release 14), and the National Biomedical Research Foundation protein sequence library (NBRF; Release 16). These searches did not disclose statistically significant similarity between the sequence obtained for CD13 and other previously sequenced proteins or DNA sequences. We did, however, identify a region spanning amino acid residues 388-392 that conforms to a pentapeptide consensus sequence, HisGlu-[Ile, Leu, Met]-X-His, which is essential for zinc coordination and the catalytic activity of metalloproteases (27-31).

Sequence comparisons with known enzymes of this class revealed virtual identity between our CD13 sequence and the recently determined sequence of aminopeptidase $N$ (32). Our CD1 3 cDNA clone includes 96 nucleotides at its $5^{\prime}$ end and 10 nucleotides plus the poly(A) sequence at its $3^{\prime}$ end that are missing from the aminopeptidase $\mathrm{N}$ clone. Within the sequenced regions of both cDNA clones, there were 10 nucleotide mismatches, only four of which result in predicted amino 


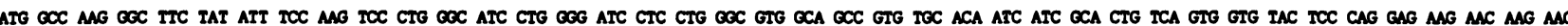

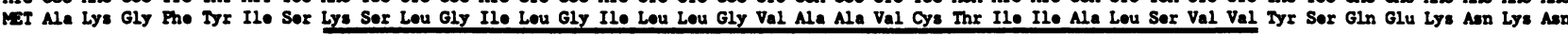

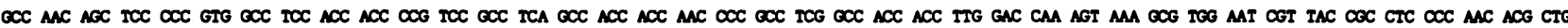
Al. Aan Ser Ser Pro val ala Sor Thr Thr Pro Sor Ala Sor Ala Thr Thr Aen Pro Ala Sor Ala Thr Thr Lou Asp Gln Sor Lys Ala Trp Asn Arg Tyr Arg Lou Pro Aen thr Lou MA COC GAT TCC IAC CANG GTG ACG CTG AGA OCG IAC CTC ACC OCC MT GAC AOG OOC CTG TAC GTT ITT AAG GEC TCC AOC ACC GTC OET ITC ACC TEC MAG GAG OCC ACT GAC GTC ATC

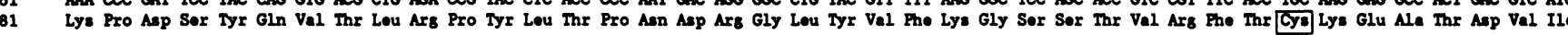

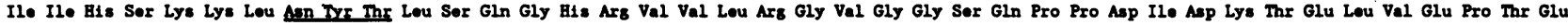

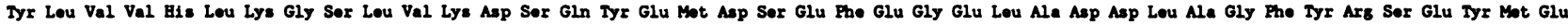

721 COC MIT GTC AGA MG GTG GTG OCC ACT ACA CAG ATG CAG OCT OCA GAT OCC CEG AMG TCC TTC OCA TEC ITC GAT GAG CCE OCC ATG AMG OCC GAG TTC AAC ATC ACG CTT ATC CAC OCC

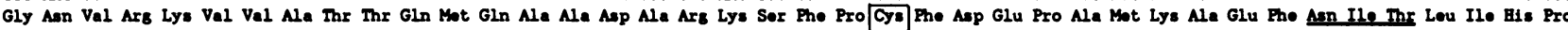

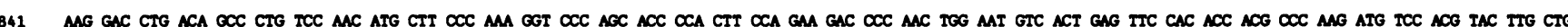

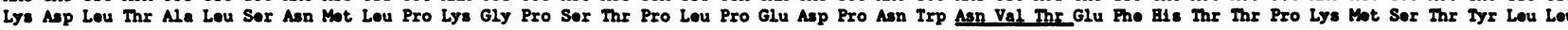

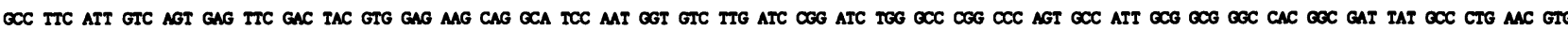

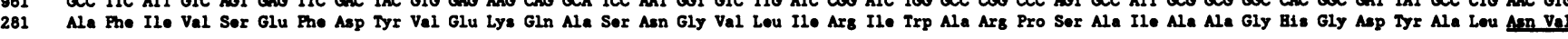

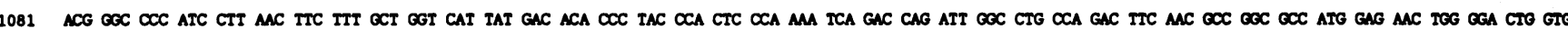

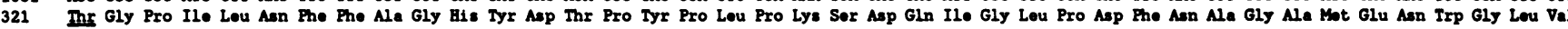

1201 ACC TAC CGG GAO MA TCC CTG CTG TTC GAC COC CTG TCC TCC TCC AOC AOC AMC AMG GAG OGG GTG GTC ACT GTG ATT GCT CAT GAG CTE COC CAC CAG TEG TTC GEG AAC CTO GTG ACC 361

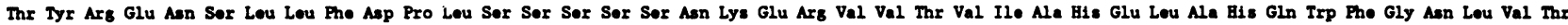
ATA GAG TGG TEG MAT GAC CTG TEG CTG AAC GAG OCC TTC OCC TCC IAC GTG GAG IAC CTG GGT OCT GAC IAT GCG GAG OCC ACC TEG MAC ITG MM GAC CTC ATG GTG CTG AT GAT GTG Il• Glu Trp Trp Asn Asp Lou Irp Lou Asn Glu Gly The Ala Sor tyr Val Glu Tyr Lou Gly Ala Asp Tyr Ala Glu Pro Thr Trp Asn Lou Lys Aap lou Mot Val Leu Asn Asp Val TAC OEC GTG ATG GCA GTG GAT OCA CTG GCC TCC TCC CAC OCG CTG TCC ACA COC OCC TCG GAG ATC AAC ACG COG GCC CAG ATC AGT GAG CTG TTT GAC OCC ATC TCC TAC AOC AMG GEC

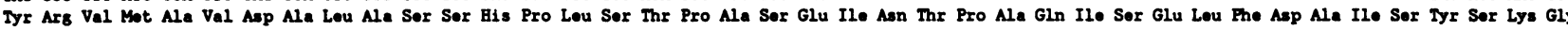

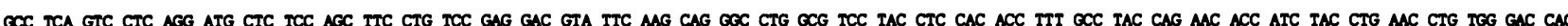

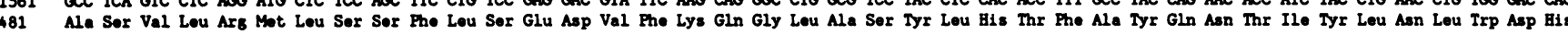
1681 CTG CAG GAG OCT GTG AMC AMC OGG TCC ATC CAN CTC CCC ACC ACC GTC COG GAC ATC ATG AAC OGC IOG ACC CTG CAG ATG GGC ITC OCG GTC ATC ACG GTG GAT ACC AGC ACG GOG ACC

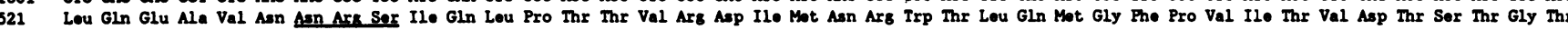
1801 CTT TCC CAG GAG CAC TTC CTC CTT GAC CCC GAT TCC AAT GTT ACC COC CCC ICA GAA ITC AAC TAC GTG TGG ATT GTG CCC ATC ACA TCC ATC AGA GAT GGC AGA CAG CAG CAG GAC TAC 561 Lou Ser Gln Glu His The Lou Lou Asp Pro Asp Ser Asn Val Ihr Arg Pro Ser Glu Phe Asn Tyr Val Trp Ile Val Pro Ile Thr Ser Ile Arg Asp Gly Arg Gln Gin Gin Asp Tyr

1921 TEG CTG ATA GAT GTA AGA GCC CAG MAC GAT CTC TTC AGC ACA TCA GEC MT GAG TEG GTC CTG CTG MAC CTC AMT GTG ACG GGC TAT TAC CGG GTG AAC TAC GAC GA GAG MC TEG AGC bo1 Irp Lou Il॰ Asp Val Arg Ala Gin Asn Asp Lou Phe Sor Thr Sor Gly Asn Glu Trp Val Lou Lou Asn Leu Asn Val Thr Gly Tyr Tyr Arg Val Asn Tyr Asp Glu Glu Asn Trp Arg

2041 AAG ATT CAG ACT CAG CTG CAG AGA GAC CAC TCG OCC ATC OCT GTC ATC AMT CEG OCA CAG ATC ATT MIT GAC GCC TTC AAC CTG GCC AGT GCC CAT MAG GTC OCT GTC ACT CTG GCG CTG

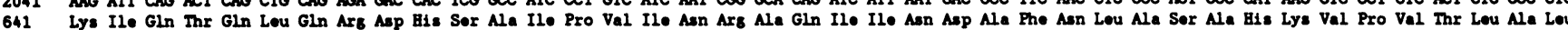

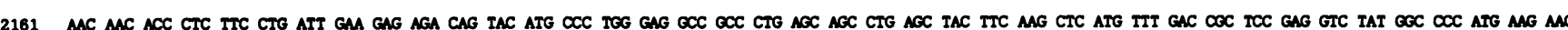

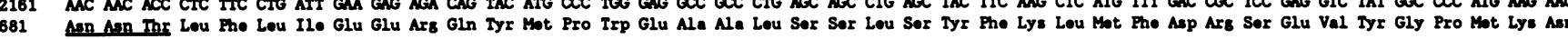

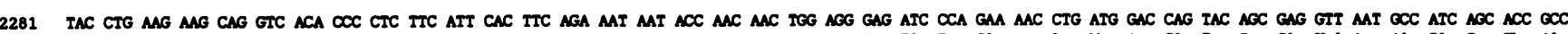

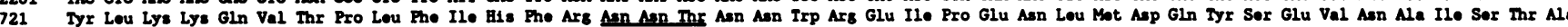

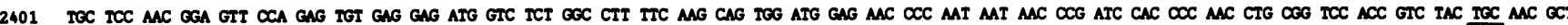

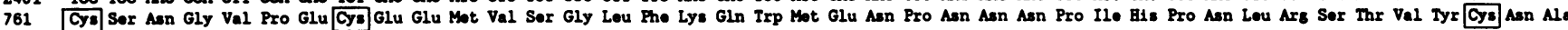

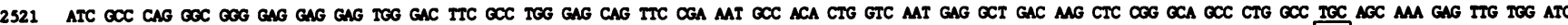
801 Ile Ala GIn Gly Gly Glu Glu Glu Trp Asp Pho Ala Irp Glu Gln Pho Ars Asn Ala Thr Lou Val Asn Glu Ala Asp Lys Lou Ars Ala Ala Lou Ale Cys Sor lys Glu Lou Irp Ilo

2641 CTG AAC AGG TAC CTG AOC TAC ACC CTG AMC CCG GAC TTA ATC COG AMG CAG GAC OCC ACC TCT ACC ATC ATC AGC ATT ACC AMC MAC GTC ATT OGG CMM GGT CTG GTC TEG GAC ITT GTC

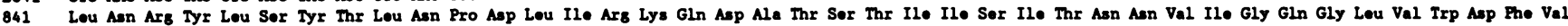

2761 CAG AGC MC TGG MG MG CTT ITT MC GAT TAT GGT GGT GOC TCG TTC TCC TTC TCC AAC CTC ATC CAG OCA GTG ACA CGA CGA TTC TCC ACC GAG IAT GAG CTG CAG CAG CTG GAG CAG

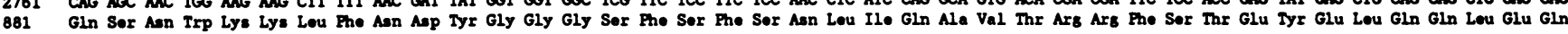

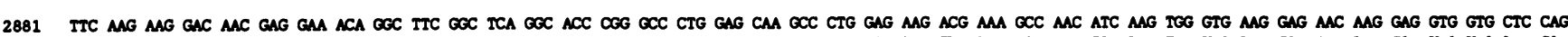

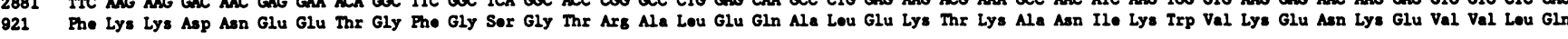

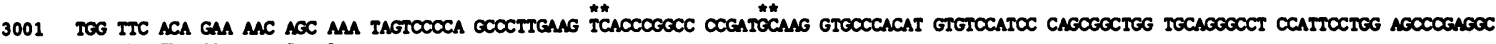
961 Trp Phe Thr Glu Asn Ser Lys

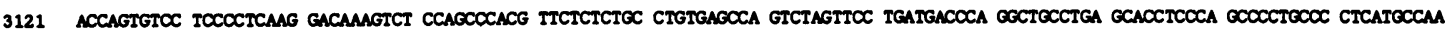

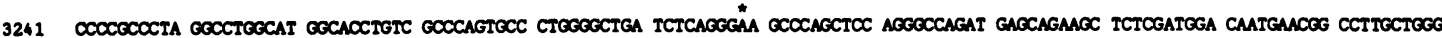

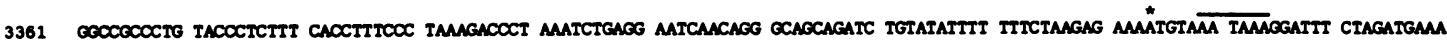

3481 AMAMMMM AMM

Figure 2. Nucleic acid sequence and deduced amino acid sequence of human CD13 cDNA. Amino acids are numbered starting at the initial methionine of the CD13 polypeptide. The hydrophobic region that functions as both a signal peptide and single transmembrane region is denoted by a double underline. The penta-peptide consensus sequence for the zinc coordinating and catalytic domain of metalloproteases (HisGlu-Leu-Ala-His) is underlined (dots). Potential sites of $\mathrm{NH}_{2}$-linked glycosylation are also underlined (solid), and cysteine residues are enclosed in boxes. The AATAAA box close to the polyadenylated $3^{\prime}$ end of the cDNA is overlined. There are 10 nucleotide mismatches between the CD13 and aminopeptidase $N(32)$ sequences, indicated by asterisks.

acid differences (Fig. 2). Accordingly, $\mathrm{Gln}^{86}$ in the CD13 sequence is predicted to be $\mathrm{Arg}^{86}$ by the aminopeptidase $\mathrm{N}$ sequence, $\mathrm{Val}^{536}$ to be $\mathrm{Glu}^{536}$, $\mathrm{Ile}^{603}$ to be $\mathrm{Met}^{603}$, and $\mathrm{Leu}^{887}$ to be Pro $^{887}$. These differences could result from naturally occurring polymorphisms or errors introduced by reverse transcriptase during cDNA synthesis.

Expression of $C D 13$ cDNA cloned in a retroviral vector. To confirm that the cDNA clones encoded bona fide gp 150 mole- 


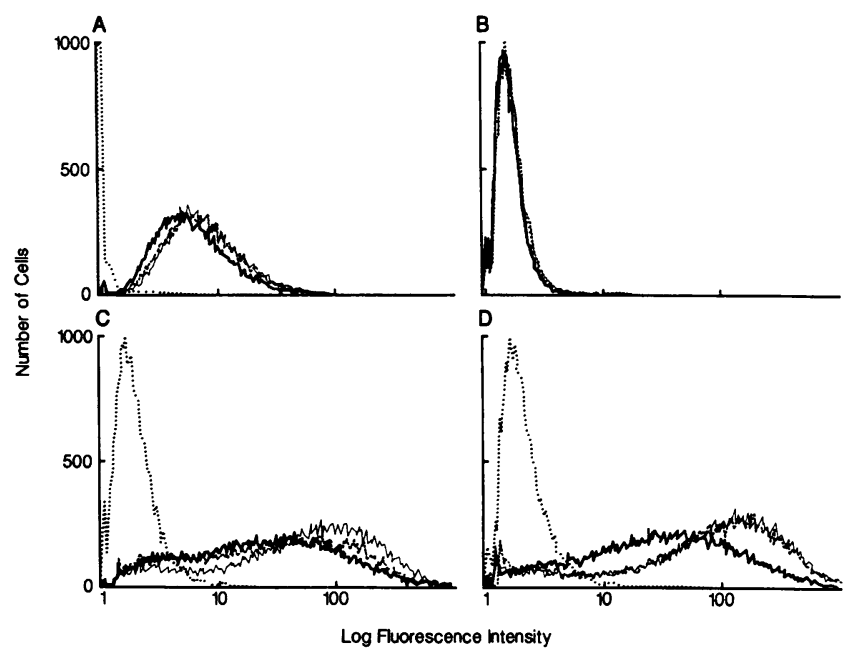

Figure 3. Expression of CD13 on the surface of NIH-3T3 cells transfected with CD13 cDNA sequences cloned in a retroviral vector. The flow cytometric profiles were obtained after binding of monoclonal antibodies specific for CD13 epitopes to HL-60 human myeloid cells $(A)$, untransfected NIH-3T3 cells $(B)$, and cells from two representative NIH-3T 3 cultures that had been transfected with complete CD13 cDNA coding sequences ( $C$ and $D$ ) reconstructed from portions of the inserts of three overlapping cDNA clones. Transfected cells were grown in G418 to select for cells expressing the neo gene of the retroviral vector and then sorted once for the $2 \%$ of cells with the brightest fluorescence after staining with the CD13-specific monoclonal antibody, MY7. Each panel shows fluorescence profiles that resulted from testing the cells with the CD13-specific monoclonal antibodies MY7 (dark solid line), SJ-1D1 (dashed line), and MCS.2 (light solid line), compared with results with a mouse myeloma protein control (dotted line).

cules, we assembled the intact coding sequences from overlapping clones and inserted them into the murine retroviral vector pZIPneoSV(X)-1 (19). The retroviral construct was transfected into NIH-3T3 cells, and the cells were cultured in medium containing G418 to select for transfectants that expressed the neo gene contained in the vector. Analysis of these cells by flow cytometry after immunofluorescence labeling with the CD13-specific monoclonal antibody MY7 disclosed that over half the cells expressed high levels of gp 150 at the cell surface. Cells that bound the highest levels of antibody were isolated by cell sorting, and cultured for further analysis. Fig. 3 shows the results of flow cytometric analysis of cells from two independently transfected cultures stained with three different CD13-specific monoclonal antibodies. The expression of gp150 epitopes by cells transfected with the retroviral vector was approximately tenfold higher than that observed for the HL-60 human myeloid leukemia cell line.

To characterize the biochemical properties of CD13 molecules expressed by cells transfected with the retroviral construct, we metabolically labeled cells with $\left[{ }^{35} \mathrm{~S}\right]$ methionine, and immunoprecipitated detergent lysates with the MY7 monoclonal antibody. High levels of polypeptides with the mobilities of gp130 and gp150 were detected in lysates from control HL-60 cells, in a tertiary mouse cell transformant (SJ-150-B) known to express high levels of gp150 $(16,22)$, and in three NIH-3T3 cultures that had been transfected with the CD13 retroviral vector (Fig. 4). No specifically precipitable polypeptide was observed in NIH-3T3 cells that were either untransfected or transfected with a plasmid containing the $\mathrm{v}$-fms oncogene. Immature gp 130 molecules had identical apparent mobilities in human HL-60 cells and in transfected mouse cells; the more rapid mobility of the mature cell surface form of the molecule in mouse cells, as compared with HL-60 cells, has been observed previously $(14,16)$ and may reflect differences in glycosylation in the different cell types.

Topology of CD13. The hydrophobicity profile predicted by the algorithm of Kyte and Doolittle (33) showed a 24 amino acid hydrophobic region, starting nine amino acids from the amino terminus, that could function as both a signal peptide and a transmembrane domain (Fig. 1). No other hydrophobic region that would be of sufficient length to span the plasma membrane was identified. This suggested that $\mathrm{CD} 13$ might be a member of a small family of integral membrane proteins, in which the signal sequence is not removed after translocation of the $\mathrm{NH}_{2}$-terminus into the lumen of the endoplasmic reticulum, but rather is retained to serve as a transmembrane anchor (34). Proteins of this type are oriented with their amino terminus in the cytoplasm and their carboxyl terminus outside the cell.

To test this hypothesis, we determined the $\mathrm{NH}_{2}$-terminal peptide sequence of both the gp130 and gp150 forms of the molecule, which were immunoprecipitated with specific antisera from lysates of HL-60 cells. The yields indicated that $\sim 10 \%$ of the molecules were susceptible to Edman degradation, and the first 20 residues matched amino acids $2-21$ of the

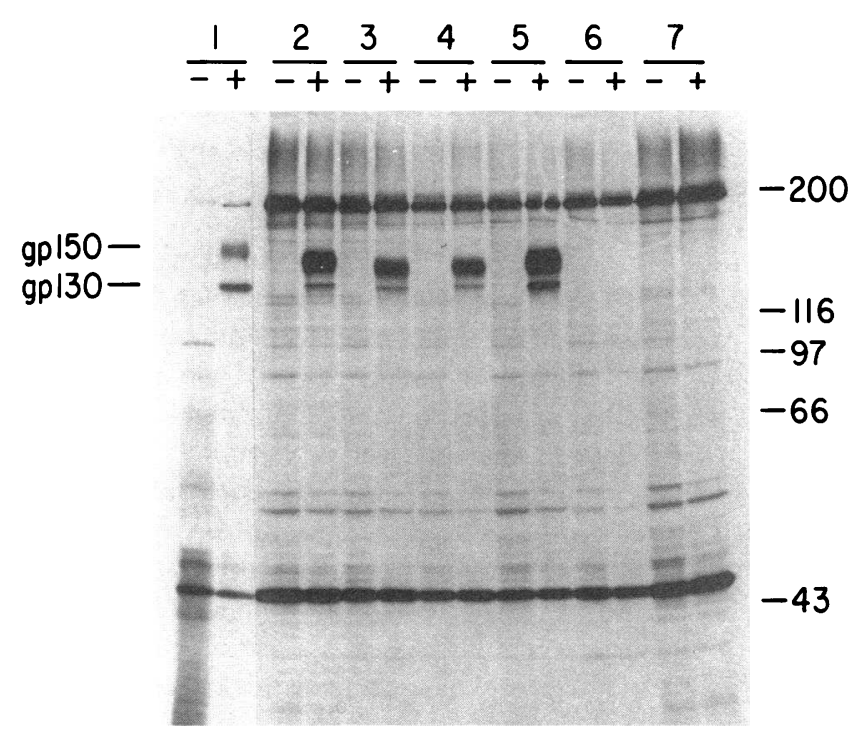

Figure 4. Biochemical characterization of gp1 30 and gp1 50 glycoproteins expressed by NIH-3T 3 cells transfected with CD13 cDNA sequences cloned in a retroviral vector. Cells were metabolically labeled with $\left[{ }^{35} S\right]$ methionine for $1 \mathrm{~h}$ and incubated an additional hour with complete medium; then, detergent lysates were immunoprecipitated with the MY7 CD13-specific monoclonal antibody (+) or with a control monoclonal antibody $(-)$. Labeled proteins in immune complexes were analyzed in polyacrylamide gels containing SDS. Results are shown for HL-60 cells (lane 1); the tertiary transformant SJ-150-B $(16,22)$, derived from serial transfections of genomic DNA with the v-fms oncogene as a selectable marker (2); NIH-3T3 cells from three cultures independently transfected with complete CD13 coding sequences cloned in a retroviral vector $(3,4$, and 5$)$; untransfected NIH-3T3 cells (6); and NIH-3T3 cells transfected with the v-fms oncogene (7). 
sequence predicted from the CD13 cDNA nucleotide sequence (Ala-Lys-Gly-Phe-Tyr-Ile-Ser-Lys-Ser-Leu-Gly-IleLeu-Gly-Ile-Leu-Leu-Gly-Val-Ala; Fig. 2). The N-terminal amino acid sequence is consistent with translation being initiated at the ATG codon predicted from the nucleic acid sequence, and indicates that the signal sequence is not cleaved after insertion of the molecules into membranes of the endoplasmic reticulum. This result is typical of integral membrane proteins whose signal sequences are retained as a transmembrane anchor. In such proteins, the amino-terminal methionine is characteristically removed, and the second residue is acetylated, leaving only a minority of unblocked amino termini that remain susceptible to Edman degradation (35-37).

\section{Discussion}

The cellular distribution and biochemical properties of CD13 glycoproteins suggested that they might have important physiologic roles, not only on myeloid cells but also on cells from the diverse tissues that bind CD13-specific monoclonal antibodies $(1,14,15)$. We undertook the molecular cloning of CD13 cDNA with the idea that the deduced primary structure of the polypeptide would provide insight into the functions of this glycoprotein on normal and malignant cells. The translated amino acid sequence predicts a polypeptide of 967 amino acids with 11 potential sites of asparagine-linked oligosaccharide addition, accounting for the $110-\mathrm{kD}$ molecular mass of the unglycosylated polypeptide and the additional mass attributable to the carbohydrate moiety of the cotranslationally modified glycoprotein $(14,15)$. Aminoterminal protein sequence analysis indicated that $\mathrm{CD} 13$ molecules are synthesized with an uncleaved signal sequence and that proteolytic processing at the amino-terminus is limited to removal of the initiator methionine. Because the retained signal sequence is the only potential membrane-spanning segment apparent from hydrophobicity analysis, CD13 glycoproteins are likely to be oriented with their amino terminus inside and their carboxyl terminus outside the cell. Integral membrane proteins with this topology include a small group of molecules that function predominately as receptors or membrane-bound enzymes (34-40). The extracellular carboxyterminal CD13 domain contains a pentapeptide signature sequence that serves as the catalytic site of zinc-binding metalloproteases, suggesting that CD13 is a membrane-bound enzyme of this class (27-31). Comparison of the recently published sequence of a cDNA clone encoding aminopeptidase $\mathrm{N}$ (32), a prominent metalloprotease, with our CD13 cDNA sequence disclosed that the two molecules are identical.

Aminopeptidase $\mathrm{N}$ (EC 3.4.11.2) is an important enzyme of the brush border membranes of the small intestine, renal proximal tubules, and placenta (41-43). Its expression has also been documented on synaptic membranes of the central nervous system (44) and on the surface of macrophages (45) and granulocytes $(46,47)$. This enzyme catalyzes the removal of $\mathrm{NH}_{2}$-terminal amino acids from peptides, with a preference for neutral residues, but with broad specificity in the cleavage of basic and acidic residues as well (48). The natural substrates appear to be peptides rather than proteins, but the enzyme is more effective in the removal of residues from oligopeptides than from dipeptides (48). In the intestinal brush border where aminopeptidase $\mathrm{N}$ constitutes $8 \%$ of the total protein, the carboxyterminal enzymatic domain faces the lumen and most likely plays an important role in the final stages of the digestion of small peptides $(41,42)$. In other tissues, the enzyme has been postulated to function in the hydrolytic inactivation of regulatory peptides, including enkephalins, that are involved in signal transduction at the cell membrane $(44,45,49)$.

The synthesis and posttranslational processing of aminopeptidase $\mathrm{N}$ have been characterized biochemically in epithelial cells from the small intestine and renal proximal tubules of the pig $(50,51)$. Pulse-chase experiments have demonstrated that newly synthesized molecules have an apparent molecular mass of $\sim 140 \mathrm{kD}$ and contain cotranslationally added asparagine-linked oligosaccharide chains that are rich in mannose. Within 30 to $60 \mathrm{~min}$ of synthesis, the side chains are remodeled to complex oligosaccharides, resulting in the $160 \mathrm{kD}$ mature form of the molecule that is expressed at the cell surface. Endoglycosidase $\mathrm{H}$ treatment of the immature form of the molecule removes the high-mannose oligosaccharide chains, and produces a polypeptide backbone of $115 \mathrm{kD}$. These results obtained by two different laboratories studying epithelial cells from separate organs of the pig, are perfectly consistent with our studies of CD13 synthesis and processing by human myeloid leukemia cell lines (14). In addition, aminopeptidase $\mathrm{N}$ has been shown to be expressed as a homodimer on the surface of intestinal epithelial cells of several species, including rat, pig, and human, but as a monomer in the rabbit $(42,43)$.

The gene encoding the common acute lymphoblastic leukemia antigen (CALLA or CD10) was recently cloned $(31,35)$, and its cDNA sequence was shown by Letarte and co-workers (31) to be identical to that of neutral endopeptidase (EC 3.4.24.11), a membrane-associated enzyme also known as metalloendopeptidase or enkephalinase $(28,52,53)$. The predicted amino acid sequences of CD13/aminopeptidase $\mathrm{N}$ and CD10/neutral endopeptidase do not show significant overall similarity; however, both molecules are integral membrane metalloproteases with the characteristic zinc-binding motif in their extracellular carboxyterminal domains (27-31). Neutral endopeptidase hydrolyzes peptide bonds at the amino side of hydrophobic amino acids (54), and is also thought to inactivate regulatory peptides at the cell surface (55-61). Both of these enzymes are expressed on epithelial cells of the renal proximal tubule and small intestine, granulocytes, stromal cells, and synaptic membranes in the central nervous system $(1,55-72)$. The two membrane-bound enzymes collaborate in the hydrolysis of oligopeptides in the small intestine $(41,42)$ and appear to act in concert to inactivate opioid peptides and enkephalins in the brain $(44,49)$, as well as tuftsin $(46,47)$ and the chemotactic peptide FMLP by neutrophils $(60,61)$. On hematopoietic cells, there are clear differences in their patterns of expression: CD10/neutral endopeptidase is uniquely expressed by early lymphoid precursors (62-65), while monocytes and committed myeloid progenitors express only CD13/ aminopeptidase $N(1-10)$. Neither enzyme is expressed by mature B or T lymphocytes. The reactivity profiles of CD13and CD10-specific antibodies with human leukemic cells rarely overlap, mirroring the lineage-specific binding pattern of these reagents to normal hematopoietic cells. CD13 is expressed on the leukemic blasts from the majority of patients with myeloid leukemia (1-10), whereas CD10 is expressed on lymphoid leukemias with the phenotype of early B cell progenitors (62-65). The identification of these differentiation antigens as membrane-bound metalloproteases suggests new avenues for testing their physiologic roles on myeloid and lym- 
phoid progenitors, and for determining their possible influence on normal and malignant hematopoietic cell development.

\section{Acknowledgments}

We thank Dr. Charles J. Sherr for his helpful advice and encouragement, Dr. Carl W. Rettenmier for assistance with the biochemical analysis of gp130 and gp150 glycoproteins, Dr. Clayton Naeve of the Molecular Resource Center for oligonucleotide synthesis and assistance with nucleic acid sequencing, Dr. Victor A. Fried for isolation of gp130 and gp150 glycoproteins, $\mathrm{NH}_{2}$-terminal amino acid sequence analysis and helpful discussions, Dr. Michelle Letarte and Dr. C. Victor Jongeneel for useful information regarding the zinc-binding motif of metalloproteases, Dr. Ove Norén for discussions regarding the roles and sequence of aminopeptidase N, Drs. Margaret A. Shipp and Ellis L. Reinherz for providing the CALLA sequence before publication, and John Gilbert for editorial review and helpful discussions. Excellent technical assistance was provided by Bart Jones, Kevin Coleman, Cheryl Trigg, Ed Wingfield, Mike Nash, Matthew Rebentisch, Alice Bell, and Shawn Kramer.

Supported in part by U. S. Public Health Service grants CA-42804 (A. T. Look) and CA-01013 (S. C. Peiper), Cancer Center Support (CORE) grant CA-21765, and the American Lebanese Syrian Associated Charities (ALSAC) of St. Jude Children's Research Hospital.

Note added in proof. The CD13/aminopeptidase N cDNA sequence has been submitted to Gen Bank, accession number M22324.

\section{References}

1. Hogg, N., and M. A. Horton. 1987. Myeloid antigens: new and previously defined clusters. In Leukocyte Typing III, Proceedings of the Third International Workshop on Human Leukocyte Differentiation Antigens. A. J. McMichael, editor. Oxford University Press, Oxford. 576-621.

2. Griffin, J. D., J. Ritz, L. M. Nadler, and S. F. Schlossman. 1981. Expression of myeloid differentiation antigens on normal and malignant myeloid cells. J. Clin. Invest. 68:932-941.

3. Bernard, A., L. Boumsell, and C. Hill. 1984. Joint report of the first international workshop on human leucocyte differentiation antigens by the investigators of the participating laboratories. In Leucocyte Typing. A. Bernard, L. Boumsell, J. Dausset, C. Milstein, and S. F. Schlossman, editors. Springer-Verlag, Berlin. 82-108.

4. McKolanis, J. R., O. J. Finn, and R. S. Metzgar. 1983. Characterization of human myelomonocytic antigens using monoclonal antibodies. In Non-HLA Antigens in Health, Aging and Malignancy. E. Cohan and D. P. Singal, editors. Alan R. Liss, New York. 145-156.

5. Griffin, J. D., J. Ritz, R. P. Beveridge, J. M. Lipton, J. F. Daley, and S. F. Schlossman. 1983. Expression of MY7 antigen on myeloid precursor cells. Int. J. Cell Cloning 1:33-48.

6. Griffin, J. D., and S.F. Schlossman. 1984. Expression of myeloid differentiation antigens in acute myeloblastic leukemia. In Leucocyte Typing. A. Bernard, L. Boumsell, J. Dausset, C. Milstein, and S. F. Schlossman, editors. Springer-Verlag, Berlin. 404-410.

7. Griffin, J. D., R. J. Mayer, H. J. Weinstein, D. S. Rosenthal, F. S. Coral, R. P. Beveridge, and S. F. Schlossman. 1983. Surface marker analysis of acute myeloblastic leukemia. Identification of differentiation-associated phenotypes. Blood. 62:557-563.

8. Sabbath, K. D., E. D. Ball, P. Larcom, R. B. Davis, and J. D. Griffin. 1985. Heterogeneity of clonogenic cells in acute myeloblastic leukemia. J. Clin. Invest. 75:746-753.

9. Griffin, J. D., R. Davis, D. A. Nelson, F. R. Davey, R. J. Mayer, C. Schiffer, O. R. McIntyre, and C. D. Bloomfield. 1986. Use of surface marker analysis to predict outcome of adult acute myeloblastic leukemia. Blood. 68:1232-1241.

10. Drexler, H. G., K. Sagawa, M. Menon, and J. Minowada. 1986.
Reactivity pattern of "myeloid monoclonal antibodies" with emphasis on MCS-2. Leuk. Res 10:17-23.

11. Sobol, R. E., R. Mick, I. Royston, F. R. Davey, R. R. Ellison, R. Newman, J. Cuttner, J. D. Griffin, H. Colins, D. A. Nelson, and C. D. Bloomfield. 1987. Clinical importance of myeloid antigen expression in adult acute lymphoblastic leukemia. N. Engl. J. Med. 316:11111117.

12. Mirro, J., T. F. Zipf, C.-H. Pui, G. Kitchingman, D. Williams, S. Melvin, S. B. Murphy, and S. Stass. 1985. Acute mixed lineage leukemia: clinicopathologic correlations and prognostic significance. Blood. 66:1115-1123.

13. Look, A. T., S. C. Peiper, and R. A. Ashmun. 1987. Binding of independently derived monoclonal antibodies to unique human myeloid differentiation antigens. In Leukocyte Typing III, Proceedings of the Third International Workshop on Human Leukocyte Differentiation Antigens. A. J. McMichael, editor. Oxford University Press, Oxford. 626-629.

14. Look, A. T., S. C. Peiper, M. B. Rebentisch, R. A. Ashmun, M. F. Roussel, C. W. Rettenmier, and C. J. Sherr. 1985. Transfer and expression of the gene encoding a human myeloid membrane antigen (gp150). J. Clin. Invest. 75:569-579.

15. Sakai, K., T. Hattori, K. Sagawa, M. Yokoyama, and K. Takatsuki. 1987. Biochemical and functional characterization of MCS-2 antigen (CD13) on myeloid leukemic cells and polymorphonuclear leukocytes. Cancer Res. 47:5572-5576.

16. Look, A. T., S. C. Peiper, M. B. Rebentisch, R. A. Ashmun, M. F. Roussel, R. S. Lemons, M. M. LeBeau, C. M. Rubin, and C. J. Sherr. 1986. Molecular cloning, expression, and chromosomal localization of the gene encoding a human myeloid membrane antigen (gp150). J. Clin. Invest. 78:914-921.

17. Holers, V. M., D. D. Chaplin, J. F. Leykam, B. A. Gruner, V. Kumar, and J. P. Atkinson. 1987. Human complement C3b/C4b receptor (CR1) mRNA polymorphism that correlates with the CR1 allelic molecular weight polymorphism. Proc. Natl. Acad. Sci. USA. 84:2459-2463.

18. Sanger, F., S. Nicklen, and A. R. Coulson. 1977. DNA sequencing with chain terminating inhibitors. Proc. Natl. Acad. Sci. USA. 74:5463-5467.

19. Cepko, C. L., B. E. Roberts, and R. C. Mulligan. 1984. Construction and applications of a highly transmissible murine retrovirus shuttle vector. Cell. 37:1053-1062.

20. Mirro, J., Jr., S. Melvin, D. Metzger, A. Look, and S. Murphy. 1984. Changes in cell surface antigen expression during myelocytic and monocytic cell differentiation. In Leucocyte Typing. A. Bernard, L. Boumsell, J. Dausset, C. Milstein, and S. F. Schlossman, editors. Springer-Verlag, Berlin. 442-446.

21. Rettenmier, C. W., M. F. Roussel, C. O. Quinn, G. R. Kitchingman, A. T. Look, and C. J. Sherr. 1985. Transmembrane orientation of glycoproteins encoded by the v-fms oncogene. Cell. 40:971981.

22. Look, A. T., S. C. Peiper, E. C. Douglass, J. M. Trent, and C. J. Sherr. 1986. Amplification of genes encoding human myeloid membrane antigens after DNA-mediated gene transfer. Blood. 67:637-645.

23. Peiper, S. C., R. A. Ashmun, and A. T. Look. 1988. Molecular cloning, expression, and chromosomal localization of a human gene encoding the CD33 myeloid differentiation antigen. Blood. 72:314321 .

24. Matsudaira, P. 1987. Sequence from picomole quantities of proteins electroblotted onto polyvinylidene difluoride membranes. $J$. Biol. Chem. 262:10035-10038.

25. Yarden, Y., J. A. Escobedo, W.-J. Kuang, T. L. Yang-Feng, T. O. Daniel, P. M. Tremble, E. Y. Chen, M. E. Ando, R. N. Harkins, U. Francke, V. A. Fried, A. Ullrich, and L. T. Williams. 1986. Structure of the receptor for platelet-derived growth factor helps define a family of closely related growth factor receptors. Nature (Lond.). 323:226-232.

26. Proudfoot, N. J., and G. G. Brownlee. 1976. $3^{\prime}$ non-coding region sequences in eukaryotic mRNA. Nature (Lond.). 263:211-214. 
27. McKerrow, J. H. 1987. Human fibroblast collagenase contains an amino acid sequence homologous to the zinc-binding site of Serratia protease. J. Biol. Chem. 262:5943.

28. Devault, A., C. Lazure, C. Nault, H. Le Moual, N. G. Seidah, M. Chretian, P. Kahn, J. Powell, J. Mallet, A. Beaumont, B. P. Roques, P. Crine, and G. Boileau. 1987. Amino acid sequence of rabbit kidney neutral endopeptidase 24.11 (enkephalinase) deduced from a complementary DNA. EMBO (Eur. Mol. Biol. Organ.) J. 6:1317-1322.

29. Devault, A., C. Nault, M. Zollinger, M-C. Fournie-Zaluski, B. P. Roques, P. Crine, and G. Boileau. 1988. Expression of neutral endopeotidase (enkephalinase) in heterologous COS-1 cells. J. Biol. Chem. 263:4033-4040.

30. Devault, A., V. Sales, C. Nault, A. Beaumont, B. Roques, P. Crine, and G. Boileau. 1988. Exploration of the catalytic site of endopeptidase 24.11 by site-directed mutagenesis: histidine residues 583 and 587 are essential for catalysis. FEBS (Fed. Eur. Biochem. Soc.) Lett. 231:54-58.

31. Letarte, M., S. Vera, R. Tran, J. B. L. Addis, R. J. Onizuka, E. J. Quackenbush, C. V. Jongeneel, and R. R. McInnes. 1988. Common acute lymphocytic leukemia antigen is identical to neutral endopeptidase. J. Exp. Med. 168:1247-1253.

32. Olsen, J., G. M. Cowell, E. Konigshofer, E. M. Danielsen, J. Moller, L. Laustsen, O. C. Hansen, K. G. Welinder, J. Engberg, W. Hunziker, M. Spiess, H. Sjöström, and O. Norén. 1988. Complete amino acid sequence of human intestinal aminopeptidase $\mathrm{N}$ as deduced from cloned cDNA. FEBS (Fed. Eur. Biochem. Soc.) Lett. 238:307-314.

33. Kyte, J., and R. F. Doolittle. 1982. A simple method for displaying the hydropathic character of a protein. J. Mol. Biol. 157:105132.

34. Wickner, W. T., and H. F. Lodish. 1985. Multiple mechanisms of protein insertion into and across membranes. Science (Wash. DC). 230:400-407.

35. Shipp, M. A., N. E. Richardson, P. H. Sayre, N. R. Brown, E. L. Masteller, L. K. Clayton, J. Ritz, and E. L. Reinherz. 1988. Molecular cloning of the common acute lymphoblastic leukemia antigen (CALLA) identifies a type II integral membrane protein. Proc. Natl. Acad. Sci. USA. 85:4819-4823.

36. Holland, E. C., J. O. Leung, and K. Drickamer. 1984. Rat liver asialoglycoprotein receptor lacks a cleavable $\mathrm{NH}_{2}$-terminal signal sequence. Proc. Natl. Acad. Sci. USA. 81:7338-7342.

37. Hunziker, W., M. Spiess, G. Semenza, and H. F. Lodish. 1986. The sucrase-isomaltase complex: primary structure, membrane-orientation, and evolution of a stalked, intrinsic brush border protein. Cell. 46:227-234.

38. Schneider, C., M. J. Owen, D. Banville, and J. G. Williams. 1984. Primary structure of human transferrin receptor deduced from the mRNA sequence. Nature (Lond.). 311:675-678.

39. McClelland, A., L. C. Kuhn, and F. H. Ruddle. 1984. The human transferrin receptor gene: genomic organization, and the complete primary structure of the receptor deduced from a cDNA sequence. Cell. 39:267-274.

40. Drickamer, K., J. F. Mamom, G. Binns, and J. O. Leung. 1984. Primary structure of the rat liver asialoglycoprotein receptor. Structural evidence for multiple polypeptide species. J. Biol. Chem. 259:770-778.

41. Norén, O., H. Sjöström, E. M. Danielsen, G. M. Cowell, and H. Skovbjerg. 1986. The enzymes of the enterocyte plasma membrane. In Molecular and Cellular Basis of Digestion. P. Desnuelle, editor. Elsevier/North-Holland, Amsterdam. 335-365.

42. Semenza, G. 1986. Anchoring and biosynthesis of stalked brush border membrane proteins: glycosidases and peptidases of enterocytes and renal tubuli. Annu. Rev. Cell Biol. 2:255-313.

43. Kenny, A. J., and S. Maroux. 1982. Topology of microvillar membrane hydrolases of kidney and intestine. Physiol. Rev. 62:91128.

44. Matsas, R., S. L. Stephenson, J. Hryszko, A. J. Kenny, and A. J.
Turner. 1985. The metabolism of neuropeptides. Phase separation of synaptic membrane preparations with Triton X-114 reveals the presence of aminopeptidase N. Biochem. J. 231:445-449.

45. Bowes, M. A., and A. J. Kenny. 1987. An immunohistochemical study of endopeptidase-24.11 and aminopeptidase $\mathrm{N}$ in lymphoid tissues. Immunology. 60:247-253.

46. Nagaoka, I., and T. Yamashita. 1980. Leucine aminopeptidase as an ecto-enzyme of polymorphonuclear neutrophils. Biochim. Biophys. Acta. 598:169-172.

47. Nagaoka, I., and T. Yamashita. 1981. Inactivation of phagocytosis-stimulating activity of tuftsin by polymorphonuclear neutrophils: a possible role of leucine aminopeptidase as an ecto-enzyme. Biochim. Biophys. Acta. 675:85-93.

48. McDonald, J. K., and A. J. Barrett. 1986. Mammalian Proteases: A Glossary and Bibliography. Vol. 2. Exopeptidases. Academic Press, New York. 59-71.

49. Turner, A. J., R. Matsas, and A. J. Kenny. 1985. Commentary: are there neuropeptide-specific peptidases? Biochem. Pharmacol. 34:1347-1356.

50. Danielsen, E. M. 1982. Biosynthesis of intestinal microvillar proteins: pulse-chase labelling studies on aminopeptidase $\mathrm{N}$ and sucrase-isomaltase. Biochem. J. 204:639-645.

51. Stewart, J. R., and A. J. Kenny. 1984. Proteins of the kidney microvillar membrane: biosynthesis of endopeptidase-24.11, dipeptidylpeptidase IV and aminopeptidases $\mathrm{N}$ and $\mathrm{A}$ in pig kidney slices. Biochem. J. 224:549-558.

52. Malfroy, B., W.-J. Kuang, P. H. Seeburg, A. J. Mason, and P. R. Schofield. 1988. Molecular cloning and amino acid sequence of human enkephalinase (neutral endopeptidase). FEBS (Fed. Eur. Biochem. Soc.) Lett. 229:206-210.

53. Malfroy, B., P. R. Schofield, W.-J. Kuang, P. H. Seeburg, A. J. Mason, and W. J. Henzel. 1987. Molecular cloning and amino acid sequence of rat enkephalinase. Biochem. Biophys. Res. Commun. 144:59-66.

54. Kerr, M. A., and A. J. Kenny. 1974. The purification and specificity of a neutral endopeptidase from rabbit kidney brush border. Biochem. J. 137:477-488.

55. Mumford, R. A., P. A. Pierzchala, A. W. Strauss, and $M$ Zimmerman. 1981. Purification of a membrane-bound metaloendopeptidase from porcine kidney that degrades peptide hormones. Proc. Natl. Acad. Sci. USA. 78:6623-6627.

56. Almenoff, J., S. Wilk, and M. Orlowski. 1981. Membrane bound pituitary metalloendopeptidase: apparent identity to enkephalinase. Biochem. Biophys. Res. Commun. 102:206-214.

57. Fulcher, I. S., R. Matasa, A. J. Turner, and A. J. Kenny. 1982. Kidney neutral endopeptidase and the hydrolysis of enkephalin by synaptic membranes show similar sensitivity to inhibitors. Biochem. J. 203:519-522.

58. Benuck, M., M. J. Berg, and N. Marks. 1982. Rat brain and kidney metalloendopeptidase: enkaphalin heptapeptide conversion to form a cardioactive neuropeptide, Phe-Met-Arg-Phe-amide. Biochem. Biophys. Res. Commun. 107:1123-1129.

59. Gafford, J., R. A. Skidgel, E. G. Erdös, and L. B. Hersch. 1983. Human kidney "enkephalinase," a neutral metalloendopeptidase that cleaves active peptides. Biochemistry. 22:3265-3271.

60. Connelly, J. C., R. A. Skidgel, W. W. Schulz, A. R. Johnson, and E. G. Erdos. 1985. Neutral endopeptidase 24.11 in human neutrophils: cleavage of chemotactic peptide. Proc. Natl. Acad. Sci. USA. 82:8737-8741.

61. Painter, R. G., R. Dukes, J. Sullivan, R. Carter, E. G. Erdos, and A. R. Johnson. 1988. Function of neutral endopeptidase on the cell membrane of human neutrophils. J. Biol. Chem. 263:9456-9461.

62. Greaves, M., D. Delia, G. Janossy, N. Rapson, J. Chessells, M. Woods, and G. Prentice. 1980. Acute lymphoblastic leukaemia associated antigen. IV. Expression on non-leukemic "lymphoid" cells. Leuk. Res. 4:15-32.

63. Janossy, G., F. J. Bollum, K. F. Bradstock, A. McMichael, N. Rapson, and M. F. Greaves. 1979. Terminal transferase-positive 
human bone marrow cells exhibit the antigenic phenotype of common acute lymphoblastic leukemia. J. Immunol. 123:1525-1529.

64. Janossy, G., F. J. Bollum, K. F. Bradstock, and J. Ashley. 1980. Cellular phenotypes of normal and leukemic hemopoietic cells determined by analysis with selected antibody combinations. Blood. $56: 430-441$.

65. Greaves, M. F., G. Hariri, R. A. Newman, D. R. Sutherland, M. A. Ritter, and J. Ritz. 1983. Selective expression of the common acute lymphoblastic leukemia (gp 100) antigen on immature lymphoid cells and their malignant counterparts. Blood. 61:628-639.

66. Platt, J. L., T. W. LeBien, and A. F. Michael. 1983. Stages of renal ontogenesis identified by monoclonal antibodies reactive with lymphohemopoietic differentiation antigens. J. Exp. Med. 157:155172.

67. Quackenbush, E. J., A. Gougos, R. Baumal, and M. Letarte. 1986. Differential localization within human kidney of five membrane proteins expressed on acute lymphoblastic leukemia cells. J. Immunol. 136:118-124.
68. Braun, M. P., P. J. Martin, J. A. Ledbetter, and J. A. Hanson. 1983. Granulocytes and cultured human fibroblasts express common acute lymphoblastic leukemia-associated antigens. Blood. 61:718-725.

69. Keating, A., C. K. Whalen, and J. W. Singer. 1983. Cultured marrow stromal cells express common acute lymphoblastic leukaemia antigen (CALLA): implications for marrow transplantation. $B r . J$. Haematol. 55:623-628.

70. Pesando, J. M., J. K. Tomaselli, H. Lazarus, and S. F. Schlossman. 1983. Distribution and modulation of a human leukemia-associated antigen (CALLA). J. Immunol. 131:2038-2045.

71. Metzgar, R. S., M. J. Borowitz, N. H. Jones, and B. L. Dowell. 1981. Distribution of common acute lymphoblastic leukemia antigen in nonhematopoietic tissues. J. Exp. Med. 154:1249-1254.

72. McCormack, R. T., R. D. Nelson, and T. W. LeBien. 1986 Structure/function studies of the common acute lymphoblastic leukemia antigen (CALLA/CD10) expressed on human neutrophils. J. Immunol. 137:1075-1082. 